\title{
RANCANG BANGUN ALAT PENGHITUNG BENIH IKAN BANDENG GELONDONGAN BERBASIS MIKROKONTROLER ATMEGA 328
}

\author{
Nur Afiyat \\ Fakultas Teknik, Program Studi Teknik Elektro \\ Universitas Qomaruddin \\ Email: nurafiyat@gmail.com \\ Muhammad Rifqi \\ Fakultas Teknik, Program Studi Teknik Elektro \\ Universitas Qomaruddin \\ Email: muhrifqi323@gmail.com
}

\begin{abstract}
ABSTRAK
Tingkat akurasi penghitungan benih ikan bandeng gelondongan sangat berpengaruh dalam proses jual beli benih ikan. Penegembangan alat penghitung benih ikan bandeng gelondongan ini meminimalisir kesalahan dalam proses penghitungan benih ikan bandeng gelondongan. Alat penghitung benih ikan bandeng gelondongan berbasis mikrokontroler atmega 328 ini terdiri dari 3 sistem yaitu: sistem mekanik yang terdiri dari akuarium penghitung, pipa penyalur, akuarium penampung dan pompa air, sistem elektrik terdiri dari mikrokontroler, sensor photodioda dan liquid crystal display (LCD), dan software yang berfungsi untuk mengendalikan alat penghitung benih ikan bandeng gelondongan. Berdasarkan hasil pengujian yang telah dilakukan alat ini mampu menghitung benih ikan bandeng gelondongan dengan baik pada beberapa tingkat kekeruhan air yang berbeda. Pada pengujian dengan tingkat kekeruhan air 3,93 NTU nilai akurasi rata-rata sebesar 95,10\%, kemudian pada pengujian dengan tingkat kekeruhan air 9,60 NTU nilai akurasi rata-rata sebesar 94,80\%, sedangkan pada pengujian dengan tingkat kekeruhan air 15,39 NTU nilai akurasi rata-rata sebesar 94,16\% serta pada pengujian dengan tingkat kekeruhan air 43,55 NTU alat tidak dapat berfungsi karena kondisi air terlalu keruh. Sehingga alat penghitung benih ikan bandeng gelondongan bisa berfungsi dengan baik walaupun media air yang digunakan mempunyai tingkat kekeruhan yang bervariasi.
\end{abstract}

Kata kunci: alat penghitung benih ikan; bandeng gelondongan; arduino atmega328; sensor photodioda.

\section{ABSTRACT}

The accuracy of counting of milkfish seedlings is very influential in the process of buying and selling fish seeds. The development of this milkfish seed counting tool minimizes errors in the process of counting milkfish seedlings. Fishmeal seed counters based on atmega 328 microcontroller consists of 3 systems: a mechanical system consisting of a counting aquarium, a conduit, a reservoir aquarium and a water pump, an electrical system consisting of a microcontroller, photodiode sensor and liquid crystal display (LCD), and software that functions to control the milkfish seed counters. Based on the results of testing that has been done this tool is able to calculate the milkfish seedling well in several different levels of turbidity of the water. In testing with water turbidity level of $3.93 \mathrm{NTU}$ the average accuracy value is $95.10 \%$, then in testing with water turbidity level $9.60 \mathrm{NTU}$ the average accuracy value is $94.80 \%$, while in testing with water turbidity level 15,39 NTU accuracy value is 94,16\% and in testing with water turbidity level of 43,55 NTU the tool cannot function because the water condition is too turbid. So that the milkfish seed counters can function well even though the water media used have varying degrees of turbidity.

Keywords: fish seed counter; milkfish seeds; arduino atmega328; photodiode sensor.

\section{PENDAHULUAN}

Ikan bandeng yang mempunyai nama latin Chanos chanos Forskal merupakan salah satu ikan konsumsi yang populer di Indonesia. Hal ini erat kaitannya dengan populasi ikan bandeng yang banyak ditemukan di perairan samudera Hindia dan samudera Pasifik yang habitatnya di terumbu karang sekitar pesisir [1]. Sektor budidaya ikan bandeng merupakan komoditas yang cukup baik dan mempunyai nilai ekonomi tinggi di wilayah kabupaten Gresik. Ikan bandeng dibudidayakan di tambak, benih ikan bandeng ditebar di tambak yang sudah disiapkan kemudian setelah dibesarkan dalam periode waktu tertentu ikan bandeng siap untuk dipanen dan dikonsumsi [2]. Pada pembudidayaan ikan bandeng, benih merupakan komponen yang cukup penting. Berdasarkan ukuran benih ikan bandeng dibedakan menjadi beberapa diantaranya adalah nener dan gelondongan. Nener adalah larva ikan 
bandeng yang berukuran kurang dari $1 \mathrm{~cm}$ sedangkan gelondangan merupakan nener yang telah dipelihara selama kurang lebih 1-2 bulan menjadi benih bandeng berukuran sekitar 5 sampai $7 \mathrm{~cm}$. Benih ikan bandeng jenis nener biasanya didapatkan dari hatchery (tempat pembenihan), sedangkan jenis gelondongan didapatkan dari pembudidaya pendederan bandeng.

Di pasaran benih bandeng baik nener maupun gelondongan dijual berdasarkan banyaknya cacahan benih yang akan dibeli oleh konsumen. Cara penghitungan gelondongan yang banyak dilakukan saat ini adalah dilakukan secara manual yaitu dengan meletakkan gelondongan ke dalam bak plastik berwarna putih kemudian di ambil menggunakan alat takar atau gayung berwarna putih juga [3]. Tujuan dari bak air dan gayung berwarna putih adalah agar gelondongan dapat terlihat dengan jelas pada saat penghitungan. Teknis penghitungan secara manual adalah gelondongan diambil dengan gayung dengan jumlah kelipatan tertentu, misalkan 5 ekor untuk sekali ambil. Selanjutnya penghitungan dilakukan oleh dua orang, orang pertama bertugas mengambil gelondongan menggunakan gayung, kemudian orang kedua bertugas mencatat berapa gayung gelondongan yang sudah dihitung. Hasilnya penghitungannya merupakan hasil kali kelipatan gelondongan yang diambil dengan jumlah perpindahan gayung. Misal jumlah gelondongan yang diambil per gayung adalah 5 ekor dan jumlah perpindahan gayung sebanyak 100 kali, maka jumlah gelondongan adalah 5 x $100=500$ ekor. Penghitungan gelondongan secara manual ini memiliki tingkat akurasi yang berbeda-beda sesuai dengan tingkat keahlian operator yang melakukan penghitungan, sehingga akan mempengaruhi akurasi jumlah benih ikan bandeng gelondongan yang diperjualbelikan.

Berdasarkan pada permasalahan penghitungan benih ikan bandeng gelondongan secara manual, maka diperlukan suatu alat penghitung benih ikan bandeng gelondongan yang mempunyai akurasi yang tinggi dan stabil. Sehingga dengan adanya alat tersebut diharapkan proses penghitungan benih ikan bandeng gelondongan bisa lebih cepat dan akurat. Pada penelitian sebelumnya telah dilakukan Perancangan Alat Penghitung Benih Ikan Lele Berbasis Mikrokontroler ATMega8, dengan menggunakan sensor photodioda [4]. Juga pernah dilakukan penelitian Perancangan Alat Penghitung Benih Ikan Berbasis Sensor Optik, pada penelitian ini menggunakan mikrokontroler ATMega8 dan sensor fototransistor [5]. Penelitian selanjutnya yang pernah dilakukan adalah Rancang Bangun Alat Penghitung Bibit Ikan Otomatis, penelitian ini menggunakan mikrokontroler Arduino Mega 2560 dan sensor photodioda [6].

Pada [4] persentase error hasil pembacaan alat masih besar diantara $0-15 \%$ dikarenakan rancangan hardware alat masih kurang sempurna sehingga mempengaruhi sistem elektronik. Hasil penelitian [5] menunjukkan nilai akurasi penghitungan alat sebesar 91.4\% dengan kesalahan $8.6 \%$ dan faktor kesalahan utama penghitungan dikarenakan kemampuan sensor yang hanya bisa membedakan antara ada dan tidak adanya cahaya yang diterima. Sehingga apabila terjadi kondisi overlapping jumlah benih ikan yang lebih dari satu, maka sensor hanya menghitung sejumlah satu benih. Sedangkan [6] penggunaan mikrokontroler Arduino Mega 2560 bisa digantikan dengan board yang lebih kecil yaitu Arduino Nano yang harganya lebih murah.

Pada penelitian ini digunakan Arduino Nano Atmega 328 dan sensor photodioda dan light emiting diode (LED) infra merah seperti pada [7] untuk merancang alat penghitung gelondongan (benih ikan bandeng). Dengan pengembangan rancangan pada hardware maupun software yang dibutuhkan sehingga diharapkan dapat menaikkan persentase akurasi menurunkan persentase error. Demikian juga untuk penggunaan Arduino Nano Atmega 328 diharapkan dapat menekan biaya pembuatan sistem elektrik alat.

\section{METODOLOGI PENELITIAN}

Untuk memperoleh hasil yang diinginkan pada penelitian ini dilaksanakan dengan beberapa tahapan. Secara garis besar tahapan-tahapan tesebut adalah analisis kebutuhan sistem, rancang bangun sistem, integrasi sistem, uji coba alat, serta pembahasan data hasil uji coba.

\subsection{Analisis Kebutuhan Sistem}

Tahap ini bertujuan untuk menentukan kebutuhan apa saja yang diperlukan untuk melakukan rancang bangun alat penghitung benih ikan bandeng gelondongan berbasis mikrokontroler Atmega 328. Kebutuhan tersebut meliputi kebutuhan untuk sistem mekanik, sistem elektrik dan kebutuhan untuk pengembangan software yang digunakan pada alat.

\subsection{Rancang Bangun Sistem}

Rancang bangun alat bangun alat penghitung benih ikan bandeng gelondongan berbasis mikrokontroler Atmega 328 ini meliputi rancang bangun sistem mekanik, rancang bangun sistem elektrik, dan pengembangan software. 


\subsubsection{Rancang Bangun Sistem Mekanik}

Sistem mekanik dirancang agar benih ikan bandeng gelondongan dapat dengan mudah diletakkan pada akuarium penghitung kemudian masuk ke pipa penyalur secara beraturan dan akuarium penampung ikan di letakkan lebih rendah dari akuarium penghitung agar ikan yang sama tidak akan terhitung dua kali.
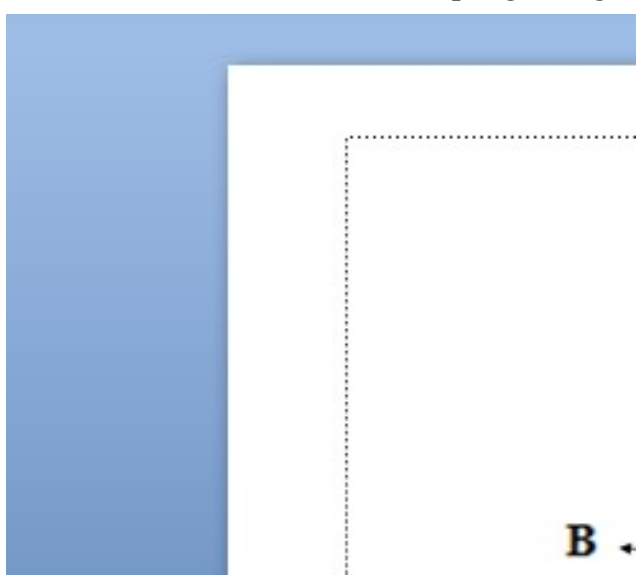

\section{Gambar 1. Rancangan Sistem Mekanik}

Pada gambar 1 merupakan rancangan mekanik dari alat penghitung benih ikan bandeng gelondongan. Ikan akan dituangkan ke akuarium penghitung secara bertahap kemudian ikan akan mengikuti aliran arus air masuk ke pipa penyalur. Untuk memperkecil kemungkinan ikan akan masuk secara bersamaan atau bergandengan dan bisa menyebabkan kesalahan hitung maka ukuran pipa yang dipakai berdiameter $2 \mathrm{~cm}$ disesuaikan dengan ukuran benih sehingga ikan dapat mengalir dengan lancar dan bisa masuk secara bergantian, serta pada setiap pipa penyalur akan diberi 2 pasang sensor yang berjarak $10 \mathrm{~cm}$. Fungsinya apabila ada ikan masuk pipa secara bersamaan atau bergandengan maka ikan terbaca sensor sendiri-sendiri atau terpisah-terpisah, sehingga tidak terjadi kesalahan hitung. Selanjutnya ikan akan jatuh ke akuarium penampung, sementara proses perhitungan berlangsung. Dan juga pada sistem mekanik ini dipasang pompa air untuk sirkulasi air supaya benih ikan bandeng gelondongan dapat mengalir dengan baik dan tidak mudah mati. Sedangkan kantong kain kasa berfungsi untuk menghindari tejadinya gelembung busa supaya tidak mengganggu proses perhitungan benih ikan bandeng gelondongan.

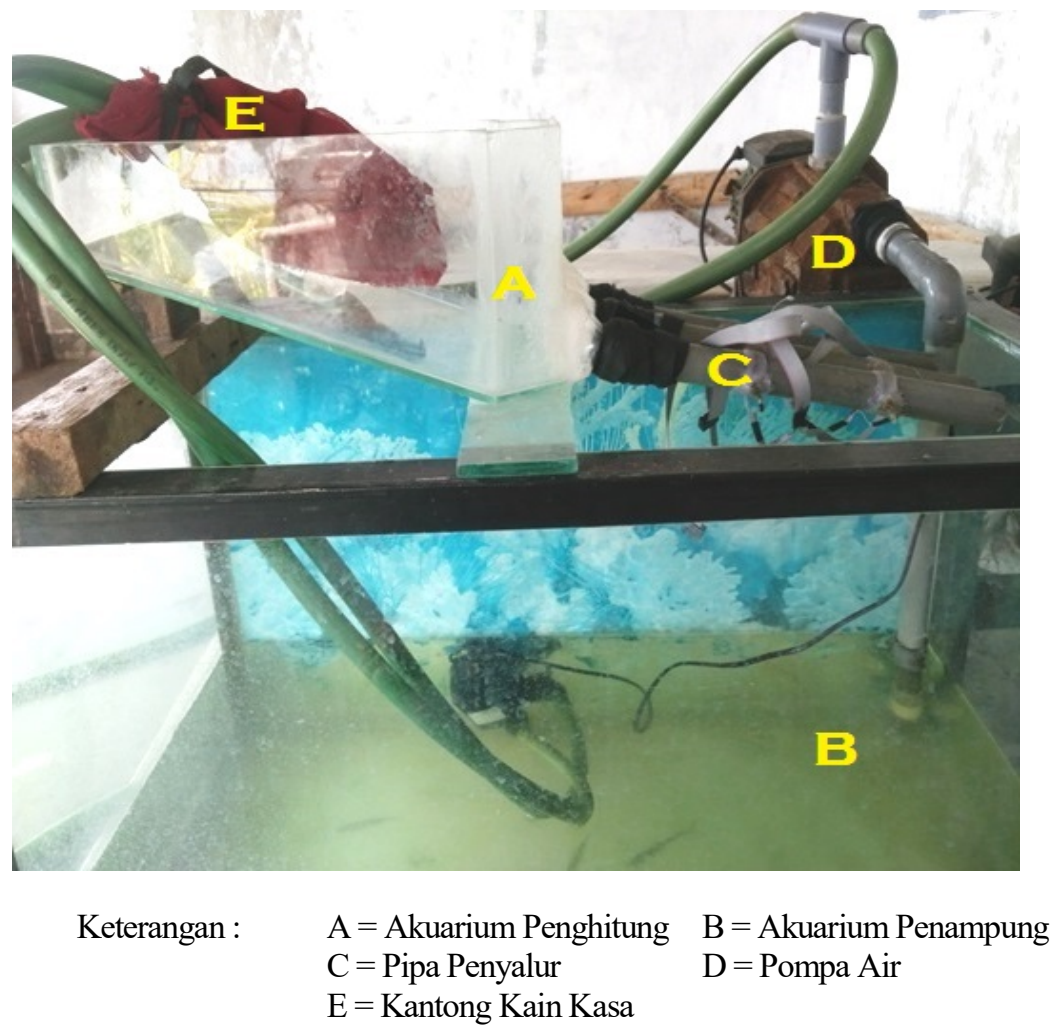

Gambar 2. Realisasi Sistem Mekanik 
Gambar 2 menunjukkan realisasi rancangan mekanik alat penghitung benih ikan bandeng gelondongan yang sudah terpasang pada alat.

\subsubsection{Rancang Bangun Sistem Elektrik}

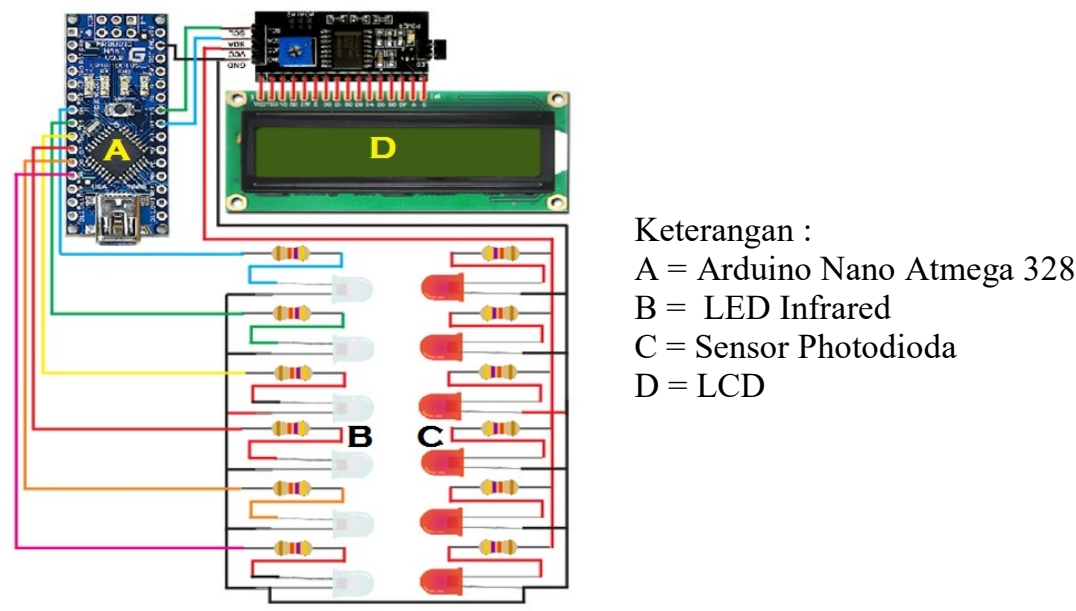

Gambar 3. Rangkaian Sistem Elektrik

Sistem elektrik pada rangkaian gambar 3 terdiri dari beberapa bagian yang penting. Bagian pertama adalah mikrokontroler Arduino Nano Atmega 328 ini merupakan bagian yang penting karena berfungsi sebagai pemroses data dari alat penghitung benih ikan ini. Bagian kedua adalah sensor untuk mendeteksi benih ikan bandeng gelondongan yang lewat pada pipa penyalur yang terdiri dari LED infrared sebagai transmitter dan sensor photodioda sebagai reciever. Bagian yang ketiga adalah LCD berfungsi untuk menampilkan hasil dari perhitungan banyaknya benih ikan bandeng gelondongan yang dihitung.

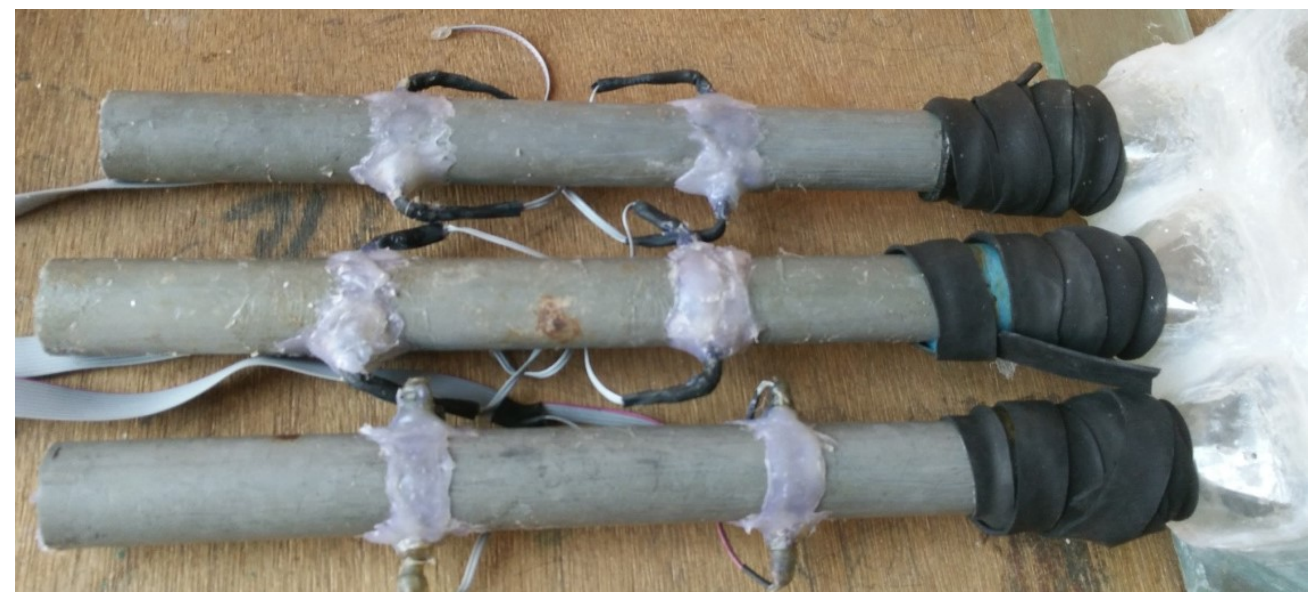

Gambar 4. Penempatan 2 Pasang Sensor Photodioda Pada Setiap Pipa Penyalur

Pada gambar 4 menunjukkan pemasangan sensor photodioda di pipa penyalur, pemasangan sensor photodiode dilakukan secara berhadapan. Pada satu pipa penyalur dipasang 2 pasang sensor photodiode dengan jarak sekitar $10 \mathrm{~cm}$, hal ini bertujuan untuk memudahkan mikrokkontroler dalam menghitung ikan yang melewati sensor apabila ikan tersebut mengalir secara bergandengan. 


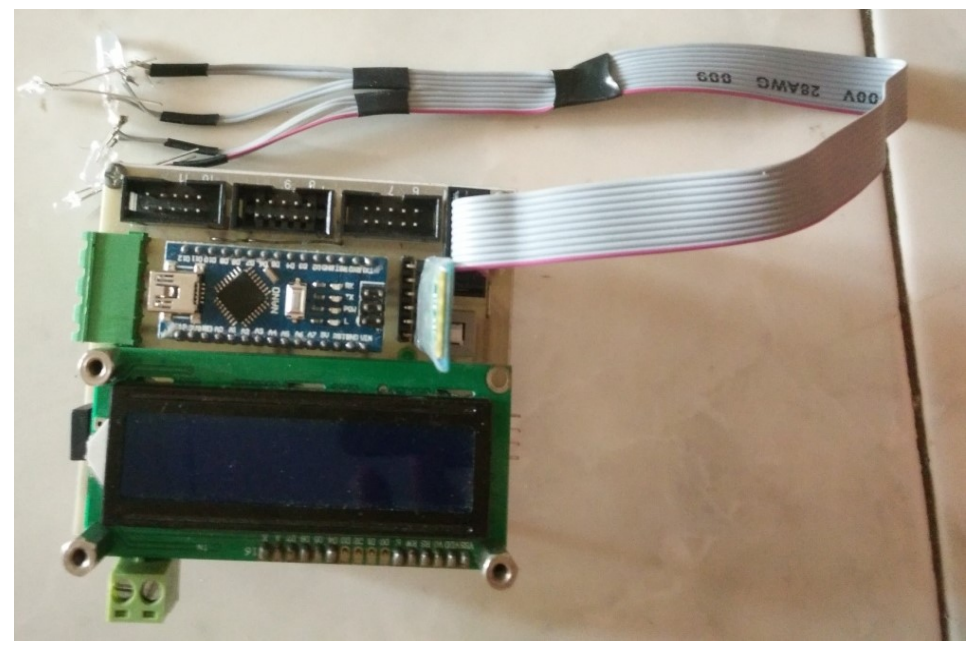

\section{Gambar 5. Realisasi Sistem Elektrik}

Pada gambar 5 menunjukkan realisasi dari sistem elektrik yang ditempatkan pada sebuah papan tunggal, yang terdiri atas mikrokontroler Arduino Nano Atmega 328, layar LCD dan beberapa konektor yang tehubung ke sensor photodioda.

\subsubsection{Perancangan Software}

Software atau program yang dikembangkan pada alat penghitung benih ikan bandeng gelondongan ini dibuat menggunakan perangkat lunak Arduino IDE. Pada software yang dibuat tersebut digunakan untuk mengolah perhitungan dari jumlah ikan yang terdeteksi oleh sensor. Pada setiap pipa penyalur terpasang 2 pasang sensor yang bertujuan untuk mendeteksi apabila ada ikan yang melewati sensor secara bergandengan sehingga mampu untuk mengurangi kesalahan dalam proses perhitungan ikan. Program yang dimasukkan dalam mikrokontroler menyesuaikan dengan data yang dibaca oleh sensor. Program dibuat berdasarkan kaidah gerbang logika EXOR dan AND dalam satu pipa penyalur.

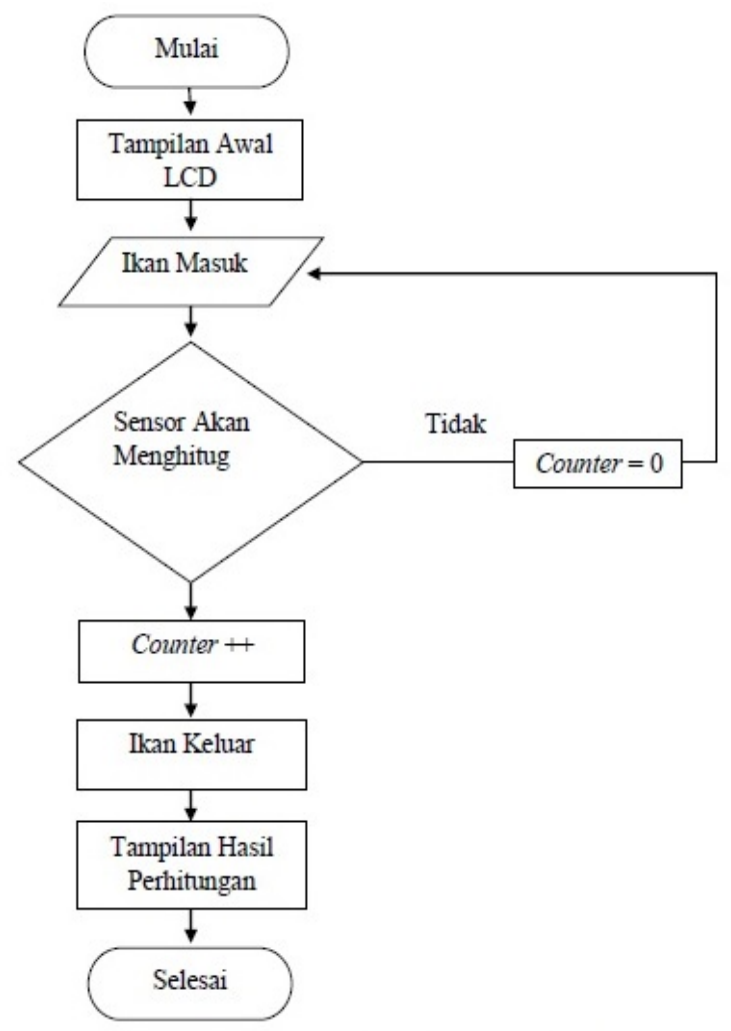

Gambar 6. Flowchart Cara Kerja Alat 
Pada gambar 6 menunjukkan flowchart cara kerja alat penghitung benih ikan bandeng gelondongan, pada saat alat diaktifkan maka LCD akan ON dengan tampilan nol hitungan, kemudian benih ikan bandeng gelondongan dimasukkan ke akuarium penghitung, selanjutnya sensor photodioda yang ada pada pipa penyalur akan menghitung setiap benih ikan bandeng gelondongan yang lewat. Setelah itu benih ikan bandeng gelondongan akan keluar menuju akuarium penampung dan hasil penghitungan benih ikan bandeng gelondongan yang dilakukan oleh sensor photodiode ditampilakan di layar LCD.

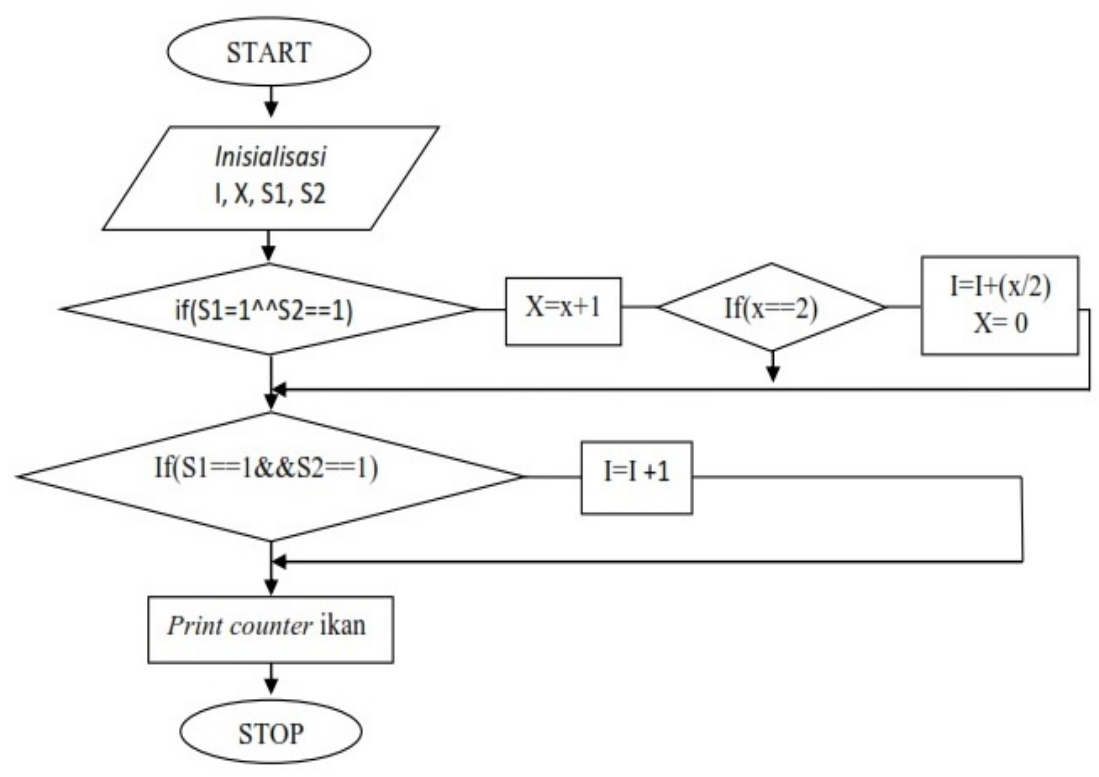

Gambar 7. Flowchart Cara Kerja Program

Pada gambar 7 menunjukkan flowchart cara kerja program alat penghitung benih ikan bandeng gelondongan dengan berdasarkan kaidah gerbang logika EXOR dan AND yang diletakkan pada masing-masing pipa penyalur.

\subsection{Integrasi Sistem}

Tahap ini bertujuan untuk menggabungkan sistem mekanik, sistem elektrik dan perangkat lunak yang sudah dirancang menjadi suatu kesatuan alat penghitung benih ikan bandeng gelondongan. Sebelum dilakukan integrasi, masing-masing komponen sistem dilakukan pengujian telah dilakukan pengujian secara terpisah. Setelah sistem berhasil diintegrasikan, maka pada tahap selanjutnya dilakukan pengujian sistem secara keseluruhan yang sudah berbentuk alat penghitung benih ikan bandeng gelondongan. Pengujian tersebut dilakukan untuk mengetahui apakah alat sudah dapat berfungsi dengan baik.

\subsection{Uji Coba Alat}

Uji coba alat meliputi uji coba sistem mekanik, uji coba sistem elektrik, uji coba software, alat ini dikatakan berhasil jika tujuan yang hendak dicapai terpenuhi. Tujuan dari penelitian ini adalah merancang bangun alat penghitung benih ikan bandeng gelondongan berbasis mikrokntroler Arduino Nano serta mengetahui nilai akurasi dan error alat. Pada penelitian ini uji coba sistem secara keseluruhan dilakukan dengan melakukan pengujian akurasi alat pada tingkat kekeruhan air yang berbeda-beda. Satuan untuk tingkat kekeruhan air yang digunakan adalah nephelometric turbidity unit atau NTU [8]. Tujuan uji coba nilai akurasi alat pada kekeruhan air yang bervariasi ini untuk mengetahui kehandalan alat terhadap adanya perubahan kekeruhan air yang digunakan dalam proses menghitung benih ikan bandeng gelondongan. 


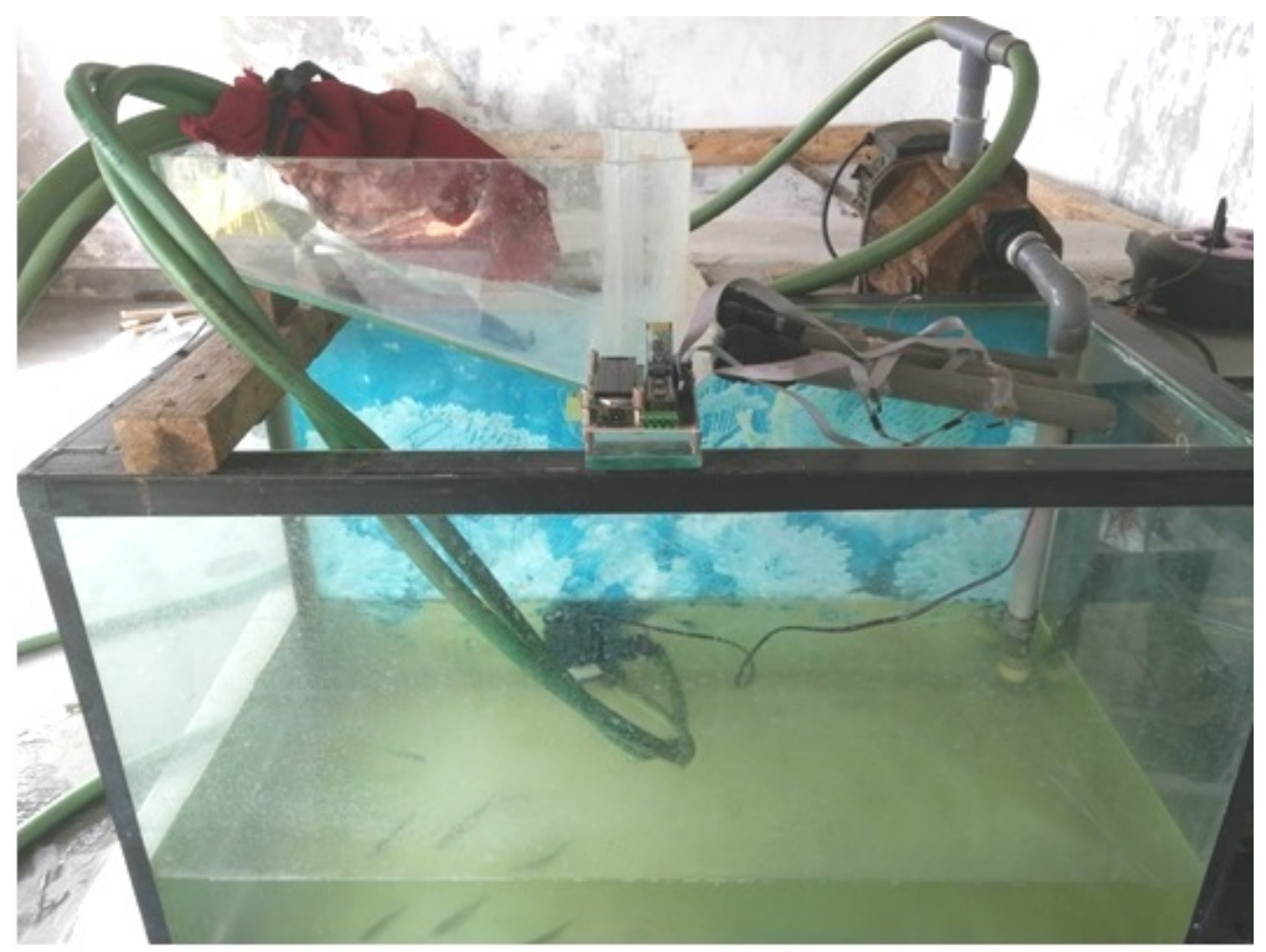

Gambar 8. Alat Penghitung Benih Ikan Bandeng Gelondongan yang Siap Diuji Coba

Pada gambar 8 menunjukkan alat penghitung benih ikan bandeng gelondongan yang siap diuji coba, pengujian dilakukan beberapa level kekeruhan air. Pengujian pertama dilakukan dengan tingkat kekeruhan air sebesar 3,93 NTU, kemudian dilanjutkan dengan tingkat kekeruhan air 9,60 NTU, selanjutnya dengan tingkat kekeruhan air 9,60 NTU, kemudian tingkat kekeruhan air 15,39 NTU, dan yang paling akhir dengan tingkat kekeruhan air sebesar 43,55 NTU. Pengujian juga dilakukan dengan menggunakan jumlah benih ikan bandeng gelondongan yang bervariasi dengan kelipatan 10, yaitu mulai dengan benih ikan bandeng gelondongan berjumlah 10 ekor sampai dengan benih ikan bandeng gelondongan berjumlah 50 ekor. Pengujian alat penghitung benih ikan bandeng gelondongan dengan menggunakan bebeapa variasi tingkat kekeruhan air bertujuan untuk mendekati kondisi real di lapangan bahwa media air yang digunakan untuk benih ikan bandeng gelondongan juga mempunyai variasi tingkat kekeruhan air yang berbeda-beda.

\section{HASIL DAN PEMBAHASAN}

Untuk mengetahui apakah alat penghitung benih ikan bandeng gelondongan dapat bekerja dengan baik dan juga untuk mengetahui tingkat akurasi dan error alat, maka diperlukan serangkaian uji coba. Hal ini dilakukan untuk mengetahui apakah sistem mekanik, sistem elektrik dan software bisa berfungsi dengan baik. Dari uji coba awal dapat dilihat bahwa pada saat kondisi air mengalir tanpa adanya ikan yang lewat maka alat tidak melakukan penghitungan sehingga LCD tetap menunjukkan angka konstan 0 , sedangkan pada saat ada ikan yang lewat maka alat mulai melakukan penghitungan sehingga LCD mulai menunjukkan angka hasil penghitungan. Dengan demikian dapat diketahui bahwa semua sistem pada alat penghitung benih ikan bandeng gelondongan dapat bekerja dengan baik.

\subsection{Uji coba alat pada tingkat kekeruhan air 3,93 NTU}

Pada uji coba ini alat penghitung benih ikan bandeng gelondongan digunakan untuk menghitung benih ikan bandeng gelondongan menggunakan air dengan tingkat kekeruhan air sebesar 3,93 NTU. Pada pengujian ini alat bisa menghitung ikan dengan baik. Untuk hasil uji coba penghitungan dengan menggunakan air pada tingkat kekeruhan 3,93 NTU dilihat pada tabel 1. 
Tabel 1. Hasil uji coba alat pada tingkat kekeruhan air 3,93 NTU

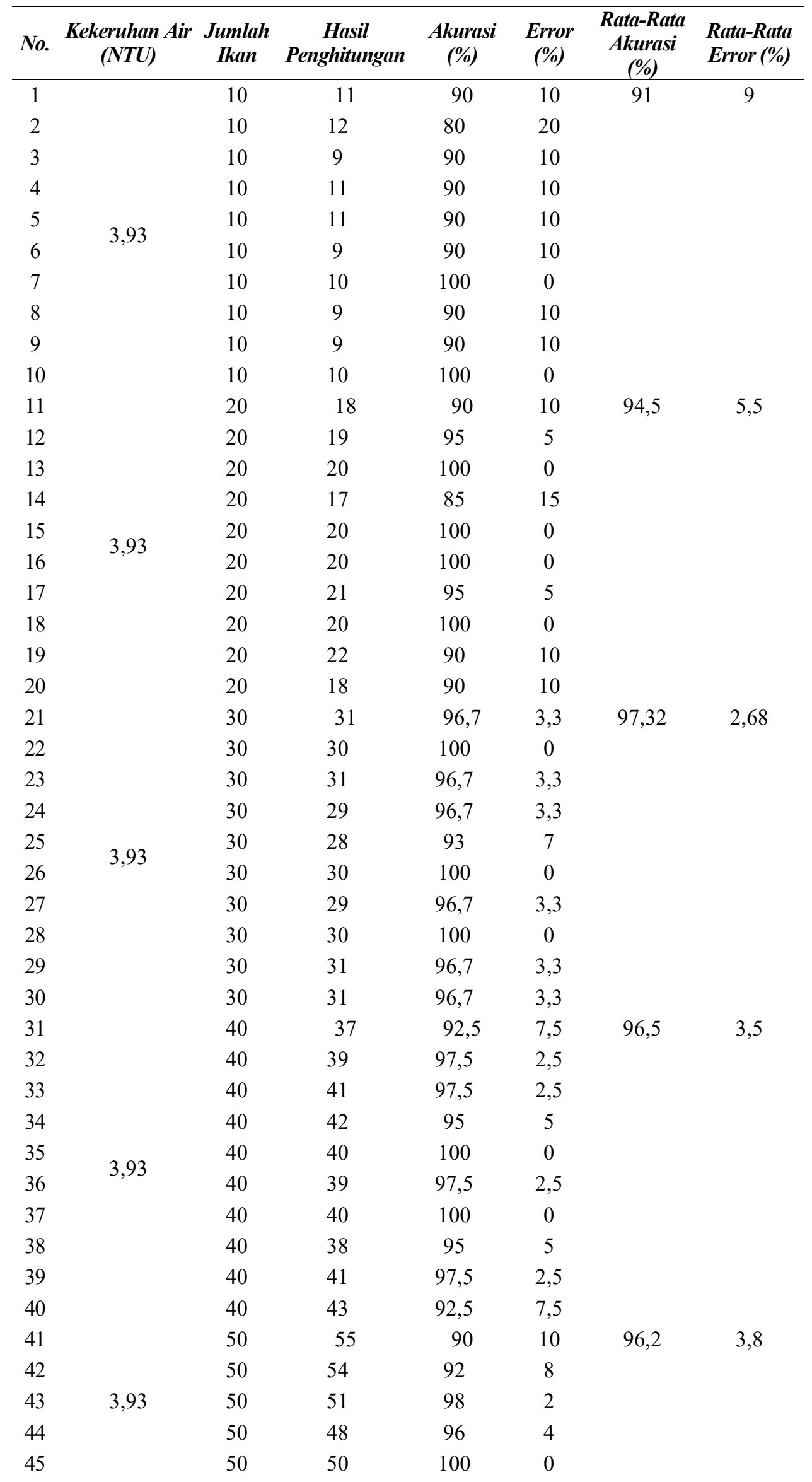




\begin{tabular}{|c|c|c|c|c|c|c|c|}
\hline No. & $\begin{array}{c}\text { Kekeruhan Air } \\
\text { (NTU) }\end{array}$ & $\begin{array}{l}\text { Jumlah } \\
\text { Ikan }\end{array}$ & $\begin{array}{c}\text { Hasil } \\
\text { Penghitungan }\end{array}$ & $\begin{array}{c}\text { Akurasi } \\
\text { (\%) }\end{array}$ & $\begin{array}{c}\text { Error } \\
(\%)\end{array}$ & $\begin{array}{c}\text { Rata-Rata } \\
\text { Akurasi } \\
\text { (\%) }\end{array}$ & $\begin{array}{l}\text { Rata-Rata } \\
\text { Error (\%) }\end{array}$ \\
\hline 46 & & 50 & 52 & 96 & 4 & & \\
\hline 47 & & 50 & 53 & 94 & 6 & & \\
\hline 48 & & 50 & 51 & 98 & 2 & & \\
\hline 49 & & 50 & 50 & 100 & 0 & & \\
\hline 50 & & 50 & 49 & 98 & 2 & & \\
\hline \multicolumn{4}{|c|}{ Rata-Rata Keseluruhan } & 95,104 & 4,896 & & \\
\hline
\end{tabular}

\subsection{Uji coba alat pada tingkat kekeruhan air 9,60 NTU}

Pada uji coba ini alat penghitung benih ikan bandeng gelondongan digunakan untuk menghitung benih ikan bandeng gelondongan menggunakan air dengan tingkat kekeruhan air sebesar 9,60 NTU. Pada pengujian ini alat bisa menghitung ikan dengan baik. Untuk hasil uji coba penghitungan dengan menggunakan air pada tingkat kekeruhan 9,60 NTU dilihat pada tabel 2 .

Tabel 2. Hasil uji coba alat pada tingkat kekeruhan air 9,60 NTU

\begin{tabular}{|c|c|c|c|c|c|c|c|}
\hline No. & $\begin{array}{c}\text { Kekeruhan Air } \\
\text { (NTU) }\end{array}$ & $\begin{array}{c}\text { Jumlah } \\
\text { Ikan }\end{array}$ & $\begin{array}{c}\text { Hasil } \\
\text { Penghitungan }\end{array}$ & $\begin{array}{c}\text { Akurasi } \\
\text { (\%) }\end{array}$ & $\begin{array}{c}\text { Error } \\
(\%)\end{array}$ & $\begin{array}{c}\text { Rata-Rata } \\
\text { Akurasi } \\
\text { (\%) }\end{array}$ & $\begin{array}{l}\text { Rata-Rata } \\
\text { Error (\%) }\end{array}$ \\
\hline 1 & \multirow{10}{*}{9,6} & 10 & 10 & 100 & 0 & \multirow{10}{*}{92} & \multirow{10}{*}{8} \\
\hline 2 & & 10 & 11 & 90 & 10 & & \\
\hline 3 & & 10 & 8 & 80 & 20 & & \\
\hline 4 & & 10 & 9 & 90 & 10 & & \\
\hline 5 & & 10 & 11 & 90 & 10 & & \\
\hline 6 & & 10 & 10 & 100 & 0 & & \\
\hline 7 & & 10 & 10 & 100 & 0 & & \\
\hline 8 & & 10 & 9 & 90 & 10 & & \\
\hline 9 & & 10 & 8 & 80 & 20 & & \\
\hline 10 & & 10 & 10 & 100 & 0 & & \\
\hline 11 & \multirow{10}{*}{9,6} & 20 & 19 & 95 & 5 & \multirow{10}{*}{93,5} & \multirow{10}{*}{6,5} \\
\hline 12 & & 20 & 19 & 95 & 5 & & \\
\hline 13 & & 20 & 21 & 95 & 5 & & \\
\hline 14 & & 20 & 20 & 100 & 0 & & \\
\hline 15 & & 20 & 21 & 95 & 5 & & \\
\hline 16 & & 20 & 23 & 85 & 15 & & \\
\hline 17 & & 20 & 21 & 95 & 5 & & \\
\hline 18 & & 20 & 19 & 95 & 5 & & \\
\hline 19 & & 20 & 22 & 90 & 10 & & \\
\hline 20 & & 20 & 22 & 90 & 10 & & \\
\hline 21 & \multirow{10}{*}{9,6} & 30 & 33 & 90 & 10 & \multirow{10}{*}{95,68} & \multirow{10}{*}{4,32} \\
\hline 22 & & 30 & 30 & 100 & 0 & & \\
\hline 23 & & 30 & 29 & 96,7 & 3,3 & & \\
\hline 24 & & 30 & 29 & 96,7 & 3,3 & & \\
\hline 25 & & 30 & 27 & 90 & 10 & & \\
\hline 26 & & 30 & 31 & 96,7 & 3,3 & & \\
\hline 27 & & 30 & 30 & 100 & 0 & & \\
\hline 28 & & 30 & 30 & 100 & 0 & & \\
\hline 29 & & 30 & 33 & 90 & 10 & & \\
\hline 30 & & 30 & 31 & 96,7 & 3,3 & & \\
\hline
\end{tabular}




\begin{tabular}{|c|c|c|c|c|c|c|c|}
\hline No. & $\begin{array}{l}\text { Kekeruhan Air } \\
\text { (NTU) }\end{array}$ & $\begin{array}{l}\text { Jumlah } \\
\text { Ikan }\end{array}$ & $\begin{array}{c}\text { Hasil } \\
\text { Penghitungan }\end{array}$ & $\begin{array}{c}\text { Akurasi } \\
(\%)\end{array}$ & $\begin{array}{c}\text { Error } \\
(\%)\end{array}$ & $\begin{array}{c}\text { Rata-Rata } \\
\text { Akurasi } \\
\text { (\%) }\end{array}$ & $\begin{array}{l}\text { Rata-Rata } \\
\text { Error (\%) }\end{array}$ \\
\hline 31 & \multirow{10}{*}{9,6} & 40 & 38 & 95 & 5 & \multirow{10}{*}{96,25} & \multirow{10}{*}{3,75} \\
\hline 32 & & 40 & 40 & 100 & 0 & & \\
\hline 33 & & 40 & 41 & 97,5 & 2,5 & & \\
\hline 34 & & 40 & 43 & 92,5 & 7,5 & & \\
\hline 35 & & 40 & 40 & 100 & 0 & & \\
\hline 36 & & 40 & 41 & 97,5 & 2,5 & & \\
\hline 37 & & 40 & 44 & 90 & 10 & & \\
\hline 38 & & 40 & 38 & 95 & 5 & & \\
\hline 39 & & 40 & 40 & 100 & 0 & & \\
\hline 40 & & 40 & 42 & 95 & 5 & & \\
\hline 41 & \multirow{10}{*}{9,6} & 50 & 51 & 98 & 2 & \multirow{10}{*}{96,6} & \multirow{11}{*}{3,4} \\
\hline 42 & & 50 & 53 & 94 & 6 & & \\
\hline 43 & & 50 & 50 & 100 & 0 & & \\
\hline 44 & & 50 & 48 & 96 & 4 & & \\
\hline 45 & & 50 & 50 & 100 & 0 & & \\
\hline 46 & & 50 & 48 & 96 & 4 & & \\
\hline 47 & & 50 & 53 & 94 & 6 & & \\
\hline 48 & & 50 & 54 & 92 & 8 & & \\
\hline 49 & & 50 & 51 & 98 & 2 & & \\
\hline 50 & & 50 & 49 & 98 & 2 & & \\
\hline \multicolumn{4}{|c|}{ Rata-Rata Keseluruhan } & 94,806 & 5,194 & & \\
\hline
\end{tabular}

\subsection{Uji Coba Alat Pada Tingkat Kekeruhan Air 15,39 NTU}

Pada uji coba ini alat penghitung benih ikan bandeng gelondongan digunakan untuk menghitung benih ikan bandeng gelondongan menggunakan air dengan tingkat kekeruhan air sebesar 15,39 NTU. Pada pengujian ini alat bisa menghitung ikan dengan baik. Untuk hasil uji coba penghitungan dengan menggunakan air pada tingkat kekeruhan 15,39 NTU dilihat pada tabel 3.

Tabel 3. Hasil Uji Coba Alat Pada Tingkat Kekeruhan Air 15,39 NTU

\begin{tabular}{ccccccc}
\hline No. $\begin{array}{c}\text { Kekeruhan Air } \\
\text { (NTU) }\end{array}$ & $\begin{array}{c}\text { Jumlah } \\
\text { Ikan }\end{array}$ & $\begin{array}{c}\text { Hasil } \\
\text { Penghitungan }\end{array}$ & $\begin{array}{c}\text { Akurasi } \\
(\%)\end{array}$ & $\begin{array}{c}\text { Error } \\
(\%)\end{array}$ & $\begin{array}{c}\text { Rata-Rata } \\
\text { Akurasi } \\
(\%)\end{array}$ & $\begin{array}{c}\text { Rata-Rata } \\
\text { Error (\%) }\end{array}$ \\
\hline 1 & 10 & 9 & 90 & 10 & 91 & 9 \\
2 & 10 & 10 & 100 & 0 & & \\
3 & 10 & 8 & 80 & 20 & \\
4 & 10 & 11 & 90 & 10 & \\
5 & 10 & 12 & 80 & 20 & \\
6 & 15,39 & 10 & 10 & 100 & 0 & \\
7 & & 10 & 100 & 0 & \\
8 & & 10 & 10 & 80 & 20 & \\
9 & & 10 & 12 & 90 & 10 & \\
10 & & 10 & 9 & 100 & 0 & \\
11 & 10 & 10 & 95 & 5 & 94 \\
12 & & 20 & 19 & 100 & 0 & \\
13 & 15,39 & 20 & 20 & 100 & 0 & \\
14 & & 20 & 18 & 90 & 10 & \\
15 & & 20 & 23 & 85 & 15 &
\end{tabular}




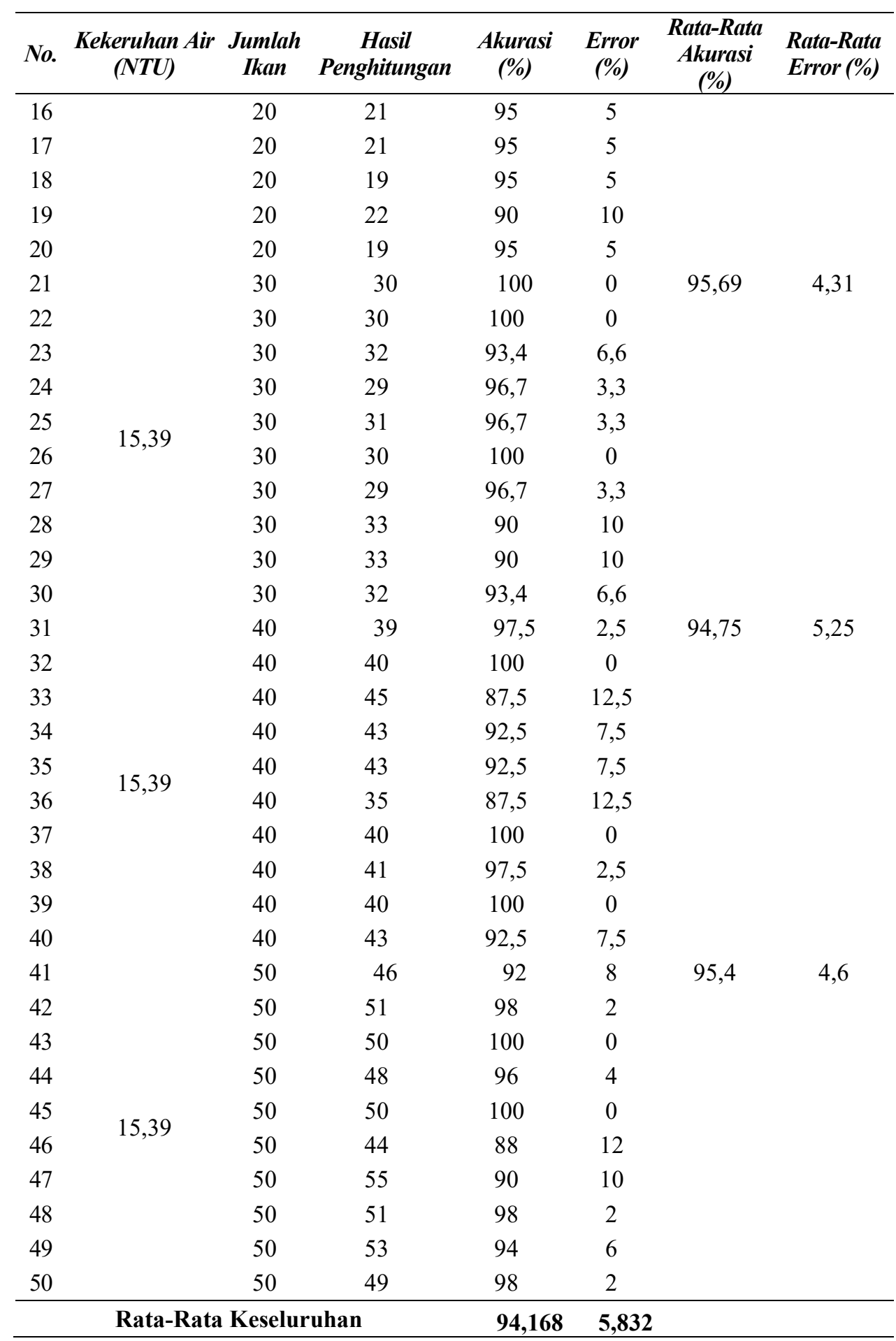

\subsection{Uji coba alat pada tingkat kekeruhan air 43,55 NTU}

Pada uji coba ini alat penghitung benih ikan bandeng gelondongan digunakan untuk menghitung benih ikan bandeng gelondongan menggunakan air dengan tingkat kekeruhan air sebesar 43,55 NTU. Pada pengujian ini sensor sudah tidak bisa menghitung ikan, hal ini dapat diketahui pada saat penghitungan, alat melakukan penjumlahan ikan secara terus menerus walaupun tidak ada ikan yang lewat pada pipa penyalur. Hal tersebut disebabkan sensor antara transmitter (LED infrared) tidak bisa menembus air dengan tingkat kekeruhan 43,55NTU, sehingga receiver (sensor photodioda) menganggap dalam kondisi ada ikan atau menghitung secara terus menerus sehingga sistem melakukan penjumlahan terus-menerus, sehingga bisa dikatakan pada kondisi ini alat tidak dapat bekerja. 


\section{KESIMPULAN}

Secara umum alat penghitung benih ikan bandeng gelondongan yang sudah dirancang bangun dapat berfungsi dengan baik. Pada uji coba menggunakan air dengan tingkat kekeruhan 3,93 NTU nilai rata-rata akurasi alat sebesar 95,10\%. Kemudian pada uji coba dengan tingkat kekeruhan air sebesar 9,60 NTU nilai rata-rata akurasi alat sebesar $94,80 \%$. Selanjutnya pada uji coba dengan tingkat kekeruhan air sebesar 15,39 NTU nilai rata-rata akurasi alat sebesar 94,16\%. Serta uji coba dengan tingkat kekeruhan air sebesar 43,55 NTU alat tidak dapat berfungsi karena kondisi air terlalu keruh.

\section{DAFTAR PUSTAKA}

[1] A. Romadon dan E. Subekti, "Teknik budidaya ikan bandeng di Kabupaten Demak," MEDIAGRO, vol. 7, no. 2, 2011.

[2] N. A. Rangka dan A. I. J. Asaad, "Teknologi budidaya ikan bandeng di sulawesi selatan," dalam Prosiding Forum Inovasi Teknologi Akuakultur, 2010, hlm. 187-203.

[3] H. Harijanto, "Tingkat Survival Rate Gelondongan Bandeng (Chanos chanos Forskal) dengan Variasi Kepadatan dalam Bak Penampungan," Neptunus, vol. 14, no. 1, 2007.

[4] P. Padiyono, "Penghitung benih ikan lele otomatis berbasis mikrokontroler atmega8," PhD Thesis, Universitas Muhammadiyah Surakarta, 2015.

[5] W. Purbowaskito dan R. Handoyo, "Perancangan Alat Penghitung Benih Ikan Berbasis Sensor Optik," Rekayasa Mesin, vol. 8, no. 3, hlm. 141-148, 2017.

[6] A. Nuggrahwanzah, "Rancang Bangun Alat Penghitung Bibit Ikan Otomatis," Tugas Akhir, Universitas Muhammadiyah Yogyakarta, 2017.

[7] S. R. Oktareza, "Simulasi Sistem Keamanan Palang Pintu Perlintasan Kereta Api Menggunakan LabVIEW," PhD Thesis, Riau University, 2015.

[8] M. Kautsar, R. R. Isnanto, dan E. D. Widianto, "Sistem Monitoring Digital Penggunaan dan Kualitas Kekeruhan Air PDAM Berbasis Mikrokontroler ATMega328 Menggunakan Sensor Aliran Air dan Sensor Fotodiode," J. Teknol. Dan Sist. Komput., vol. 3, no. 1, hlm. 79-86, 2015. 